\title{
Laparoscopic liver resection for hepatocellular carcinoma
}

\author{
Massimo Giacca, Daniel Cherqui \\ Hepatobiliary Center, Paul Brousse Hospital-Assistance Publique-Hopitaux de Paris, Universite' Paris Sud, Villejuif 94800 , \\ France.
}

Correspondence to: Dr. Massimo Giacca, Hepatobiliary Center, Paul Brousse Hospital-Assistance Publique-Hopitaux de Paris, Universite' Paris Sud, Villejuif 94800, France. E-mail: massimogiacca4@gmail.com

How to cite this article: Giacca M, Cherqui D. Laparoscopic liver resection for hepatocellular carcinoma. Hepatoma Res 2018;4:47. http://dx.doi.org/10.20517/2394-5079.2018.79

Received: 16 Jun 2018 First Decision: 9 Jul 2018 Revised: 18 Jul 2018 Accepted: 22 Jul 2018 Published: 17 Aug 2018

Science Editor: Guang-Wen Cao Copy Editor: Jun-Yao Li Production Editor: Cai-Hong Wang

\begin{abstract}
Hepatocellular carcinoma (HCC) represents the most common indication of laparoscopic liver resection (LLR). It must be acknowledged that most series concern minor hepatectomies for peripheral lesions located in favorable segments, and such procedures are now performed in the majority of HPB centers. However, there are growing reports concerning major hepatectomies (i.e., 3 segments or more) and complex resections such as anatomical resections in difficult segments (i.e., postero-superior). Retrospective comparative studies, including some with propensity score matching, and meta-analyses showed that LLR is associated with short-term benefits including reduced blood loss, length of stay and morbidity with identical oncological results and survival rates. In addition, laparoscopy leads to less post-operative abdominal adhesions, improving operative outcomes in case of repeat hepatectomy or secondary liver transplantation. Despite the lack of results of randomized-controlled trials in HCC, a consensus exists that the laparoscopic approach can improve the outcome of major liver resections, provided it is performed in experienced centers. This requires specific high-quality training.
\end{abstract}

Keywords: Laparoscopy, hepatocellular carcinoma, cirrhosis, hepatectomy, liver resection

\section{INTRODUCTION}

Since 2000, when the first case-series was published ${ }^{[1]}$, laparoscopic liver resection (LLR) has represented a growing challenge. The number of resections and the extension to major hepatectomies and difficult locations have increased worldwide over the last 10 years. In contrast with other procedures, liver resections address

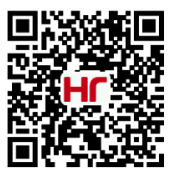


various diseases including primary and secondary liver cancer on normal or diseased underlying liver. Furthermore, different types of resections including major and minor hepatectomies can be performed, which include various procedures according to tumor type and location in the liver segments. The only available Randomized Control Trial (RCT) concerns LLR for colorectal liver metastases ${ }^{[2]}$. Results from this RCT confirmed previous retrospective reviews and meta-analyses by demonstrating benefits of LLR compared to open resection, such as reduced blood loss, morbidity and hospital stay. Two international consensus conferences on laparoscopic liver surgery were held in Louisville (USA) in 2008 and in Morioka (Japan) in 2014 ${ }^{[3,4]}$. The conclusions of the Morioka meeting validated minor LLRs as standard practice in surgery, while complex anatomical resections and major LLRs were still in an exploratory phase. The Morioka consensus also focused on underlining how major LLRs require high-level skills and emphasizing that a structured training should be performed, together with the establishment of a scoring system to evaluate difficulty before surgery. Currently, a laparoscopic approach seems applicable in $20 \%-50 \%$ of liver resections, certainly depending on local experience and skills ${ }^{[5]}$. Authors of the largest review and metaanalysis published so $\mathrm{far}^{[6]}$, with data from 9000 patients, propose LLRs as a feasible alternative to open liver resection (OLR) mainly in patients undergoing a minor resection or in those undergoing a major liver resection without biliary or vascular reconstruction. At present, LLR is accepted worldwide, with favorable outcomes compared to OLR, mainly in terms of length of stay, blood loss and post-operative complications, with comparable oncological and survival outcomes.

Almost 90\% of HCCs evolve from chronic liver disease, with different prevalent etiologies in the Eastern and Western world. Several medical and surgical approaches or, more often, combinations of these, are used to treat HCC, but surgical resection and liver transplant play the main role. Sixty-five percent of LLRs are performed for malignant disease, with HCC remaining the main indication. This is in part attributable to the large contribution of Asian literature where HCC resection is very common, and also the accurate surveillance and screening programs which allow detection, in a growing number of cases, of small single tumors which are the best candidates for $\operatorname{LLR}^{[5]}$.

\section{OPERATIVE AND POST-OPERATIVE OUTCOMES}

The first series of LLRs for HCC on cirrhosis studying both short-term outcomes and survival rates was published in $2006^{[7]}$. It concluded that LLR in selected patients with peripheral HCC on chronic liver disease was a safe procedure with good midterm results. More recent studies confirmed these results especially in cirrhotic patients ${ }^{[8-14]}$. Meta-analyses proved that patients with HCC undergoing LLR have reduced intraoperative blood loss and length of stay when compared to those undergoing $\operatorname{OLR}^{[15,16]}$. A systematic review and meta-analysis on LLR $v s$. OLR for HCC was published in 2013 by Yin et al. ${ }^{[1]}$ This study included 1238 patients from 15 studies, all requiring left lateral or right peripheral resection. Together with reduced intraoperative blood loss, it showed a lower rate of post-operative morbidity in patients undergoing laparoscopic resections. There was no significant difference in terms of survival, both overall survival (OS) and diseasefree survival (DFS). Two studies comparing laparoscopic and open resections for HCC using the propensity score were published in $2015^{[17,18]}$. The one by Han et al ${ }^{[17]}$ showed no inferiority of LLR, with similar 1,3 and 5 -year OS and DFS rates, lower post-operative morbidity and post-operative transient liver failure. These groups of patients had comparable operative times. A study by Takahara et al. ${ }^{[18]}$ showed similar results with reduced blood loss, post-operative morbidity, ascites and liver failure in patients who underwent LLR. In this group of patients operative time was longer and oncological results comparable.

\section{MAJOR HEPATECTOMIES}

In recent years the laparoscopic approach has extended to major hepatectomies. In 2017, Yoon et al. ${ }^{[13]}$ in a propensity-score analysis comparing patients who had laparoscopic and open right hepatectomy for HCC 
on cirrhosis, demonstrated better results in the laparoscopic group for length of hospital stay, level of postoperative pain and ascites. Rate of incisional hernia was also lower in this group. These authors used the comprehensive complication index (CCI) to prove a significantly less severe overall morbidity. They showed no significant difference in terms of intra-operative blood loss. None of the patients in both groups required transfusions. In the Yoon's cohort of patients, operative time was significantly shorter in the open group. The main limits of this study are that it is not an RCT and that the great majority of patients (more than 90\%) had HBV-related cirrhosis. We are of the opinion that patients with HCC on chronic hepatitis B may offer a less challenging setting for resection and less post-operative complications when compared to other etiologies of cirrhosis ${ }^{[19]}$.

Another recent propensity-score study by $\mathrm{Xu}$ et al. ${ }^{[20]}$ compared the laparoscopic and open approaches for major hepatectomies to treat HCC on cirrhosis. This study, which included 103 patients, confirmed a lower occurrence of post-operative ascites and showed no difference in all other medical and surgical postoperative complications. A lower post-operative occurrence of ascites had already been observed by other authors and described in meta-analyses ${ }^{[15,16,21]}$. Also in the Xu's series, the open group had significantly lower operative and Pringle times, while the laparoscopic group showed a significantly shorter length of stay and a higher overall cost of hospitalization.

A study that aimed at comparing laparoscopic and OLR for HCC following sequential trans-arterial chemoembolization (TACE)-portal vein embolization (PVE) was published by Goumard et al. ${ }^{[22]}$ The results from this study showed no difference in oncological radicality in terms of Ro resections and tumor margins. LLRs were proven to offer shorter length of stay and fewer grade B post-operative liver failures.

Results from the first Asia Pacific consensus meeting of LLR for HCC were published in $2018^{[23]}$. The meeting of experts produced 22 recommendations, concluding that minor LLRs should be performed in experienced centers and major LLRs in centers of excellence. In these selected centers LLR with portal vein reconstruction is also possible if vascular involvement only targets the left lateral branches. The meeting's conclusions also mention some of the new frontiers of LLRs, such as the use of indocyanine green fluorescence and robotic resection, which could become high-quality tools to optimize surgery in the near future.

\section{CONVERSION RATES}

Another main-point of interest in evaluating the feasibility of LLRs for HCC is conversion rate. Goumard et al. ${ }^{[22]}$ had a higher conversion rate compared to the other studies, reaching $25 \%$ but never in an emergency setting. These authors defined conversion criteria as: significant bleeding, failure to accurately recognize the biliary anatomy and poor exposure leading to failure or slow progression during parenchymal transection. Work from other authors showed conversion rates ranging from $5 \%$ to $13 \%{ }^{[14,17,24]}$. The largest available case series in all LLRs for HCC is a retrospective analysis by Dagher et al ${ }^{[25]}$, which presented a conversion rate of $10 \%$. A recent retrospective analysis of 2861 cases of LLRs by Halls et al. ${ }^{[26]}$ showed a conversion rate of $7.8 \%$, in which bleeding was the most common cause. Almost $19 \%$ of conversions were due to adhesions. In this series, $11.5 \%$ of patients had cirrhosis and a conversion rate of $11.1 \%$, which turned out to be statistically significant when compared to the conversion rate of $7.3 \%$ in non-cirrhotic patients.

\section{ONCOLOGICAL OUTCOMES}

In all studies, there was no evidence of inferiority of LLR in terms of oncological results and survival rates, both OS and DFS ${ }^{[13,14,17,18,20,27]}$. Moreover, the work by Han et al. ${ }^{[17]}$ compared the laparoscopic and open groups in terms of pathological liver status, tumor size and satellites, microvascular and capsular invasion, tumor grade and stage. No significant difference was found. Recently, a retrospective study by 
Woo-Hyoung et al. ${ }^{[28]}$ analyzed 234 patients undergoing anatomical LLR for HCC: DFS was $67.5 \%$ and $55.3 \%$, OS was $91.7 \%$ and $87.1 \%$ at 3 and 5 years respectively. In this work anatomical resection emerged as a good prognostic factor for HCC recurrence, but had no impact on the OS. Another recent study by Guro et al. ${ }^{[29]}$ considered retrospectively 177 patients who underwent major LLR or OLR, finding the early ( $<1$ year) recurrence rate to be significantly higher in the open group, with similar OS and DFS rates. Population in this study also showed a larger tumor size in the open group, which could explain the better results in the laparoscopic one.

\section{FEASIBILITY OF LLR}

Although postero-superior segments (1,4a, 7 and 8) are known to be the less accessible ones, recent literature leans toward the concept that tumor location should no longer be a criteria for patient selection in laparoscopic surgery ${ }^{[30,31]}$. Already in 2010 , Yoon et al. ${ }^{[32]}$ published a retrospective study comparing postero-superior (PS) and antero-lateral (AL) resections for HCC. The study concluded that PS patients had longer operative time and length of hospital stay, but no significant difference in terms of post-operative morbidity, recurrence or survival. A non-significant tendency towards a higher rate of conversion was shown in PS patients.

In 2012, Ishizawa et al. ${ }^{[33]}$ analyzed 62 patients who had resections in all segments, confirming that PS resections require longer operative time and are also affected by higher blood loss. The authors proved accurate LLR to be feasible in all segments, but considered PS resections as "difficult segmentectomies" which should be performed by surgeons with advanced open and laparoscopic experience.

Last, the laparoscopic approach reduces the formation of post-operative adhesions. This appeared, in the case of repeat hepatectomy, to reduce operative time and difficulty of the adhesiolysis which could impact on peri-operative morbidity in terms of bleeding and bowel or other organ injuries ${ }^{[13,34]}$. This suggests that LLRs should be preferred, when feasible, considering the risk of recurrence and especially in potential candidates for liver transplant ${ }^{[35]}$.

\section{LLR VS. ABLATION}

Regarding single small HCCs, several authors have debated whether to perform laparoscopic resection or local ablation. OLR was shown to be associated to higher rate of complications, greater blood loss and longer hospital stay compared to radiofrequency ablation (RFA) ${ }^{[23,36,37]}$. These disadvantages are likely to be reduced in laparoscopic resections. LLR seems to have better oncological results, in terms of lower recurrence rates, when compared to RFA for the treatment of small $(<3 \mathrm{~cm}) \mathrm{HCCs}^{[23,38-40]}$. OS in the two procedures do not differ significantly ${ }^{[39,41]}$.

The main limitations of this study are that it was a single-center non-systematic review.

\section{CONCLUSION}

In conclusion, data have been accumulated in the recent literature in favor of safety and reliability of LLR for HCC, especially in a cirrhotic setting. Currently, while LLR is the standard practice for patients requiring minor hepatectomies, evidence regarding the feasibility of major LLRs is growing. Several studies also show short-term benefits of LLR for major hepatectomies, with identical oncological results. A particular advantage in the cirrhotic patient is a lower risk of postoperative decompensation and ascites. Still, these operations are mainly performed in experienced centers. The next challenge will be the dispatch and training of surgeons in accordance to these procedures, in order to achieve a meaningful improvement in patient care and clinical outcomes. 


\section{DECLARATIONS}

\section{Authors' contributions}

Concept and design of study or acquisition of data or analysis and interpretation of data; drafting the article or revising it critically for important intellectual content; final approval of the version to be published: Giacca M, Cherqui D

\section{Availability of data and materials}

Not applicable.

\section{Financial support and sponsorship}

None.

\section{Conflicts of interest}

Both authors declared that there are no conflicts of interest.

\section{Ethical approval and consent to participate}

Not applicable.

\section{Consent for publication}

Not applicable.

\section{Copyright}

(c) The Author(s) 2018.

\section{REFERENCES}

1. Cherqui D, Husson E, Hammoud R, Malassagne B, Stéphan F, Bensaid S, Rotman N, Fagniez PL. Laparoscopic liver resections: a feasibility study in 30 patients. Ann Surg 2000;232:753-62.

2. Fretland ÅA, Dagenborg VJ, Bjørnelv GMW, Kazaryan AM, Kristiansen R, Fagerland MW, Hausken J, Tønnessen TI, Abildgaard A, Barkhatov L, Yaqub S, Røsok BI, Bjørnbeth BA, Andersen MH, Flatmark K, Aas E, Edwin B. Laparoscopic versus open resection for colorectal liver metastases: the OSLO-COMET randomized controlled trial. Ann Surg 2018;267:199-207.

3. Buell JF, Cherqui D, Geller DA, O’Rourke N, Iannitti D, Dagher I, Koffron AJ, Thomas M, Gayet B, Han HS, Wakabayashi G, Belli G, Kaneko H, Ker CG, Scatton O, Laurent A, Abdalla EK, Chaudhury P, Dutson E, Gamblin C, D’Angelica M, Nagorney D, Testa G, Labow D, Manas D, Poon RT, Nelson H, Martin R, Clary B, Pinson WC, Martinie J, Vauthey JN, Goldstein R, Roayaie S, Barlet D, Espat J, Abecassis M, Rees M, Fong Y, McMasters KM, Broelsch C, Busuttil R, Belghiti J, Strasberg S, Chari RS; World Consensus Conference on Laparoscopic Surgery. The international position on laparoscopic liver surgery: the Louisville statement, 2008. Ann Surg 2009;250:825-30.

4. Wakabayashi G, Cherqui D, Geller DA, Buell JF, Kaneko H, Han HS, Asbun H, O’Rourke N, Tanabe M, Koffron AJ, Tsung A, Soubrane O, Machado MA, Gayet B, Troisi RI, Pessaux P, Van Dam RM, Scatton O, Abu Hilal M, Belli G, Kwon CH, Edwin B, Choi GH, Aldrighetti LA, Cai X, Cleary S, Chen KH, Schön MR, Sugioka A, Tang CN, Herman P, Pekolj J, Chen XP, Dagher I, Jarnagin W, Yamamoto M, Strong R, Jagannath P, Lo CM, Clavien PA, Kokudo N, Barkun J, Strasberg SM. Recommendations for laparoscopic liver resection: a report from the second international consensus conference held in morioka. Ann Surg 2015;261:619-29.

5. Cherqui D. Evolution of laparoscopic liver resection. Br J Surg 2016;103:1405-7.

6. Ciria R, Cherqui D, Geller DA, Briceno J, Wakabayashi G. Comparative short-term benefits of laparoscopic liver resection: 9000 cases and climbing. Ann Surg 2016;263:761-77.

7. Cherqui D, Laurent A, Tayar C, Chang S, Van Nhieu JT, Loriau J, Karoui M, Duvoux C, Dhumeaux D, Fagniez PL. Laparoscopic liver resection for peripheral hepatocellular carcinoma in patients with chronic liver disease: midterm results and perspectives. Ann Surg 2006;243:499-506.

8. Belli G, Limongelli P, Fantini C, D’Agostino A, Cioffi L, Belli A, Russo G. Laparoscopic and open treatment of hepatocellular carcinoma in patients with cirrhosis. Br J Surg 2009;96:1041-8.

9. Ker CG, Chen JS, Kuo KK, Chuang SC, Wang SJ, Chang WC, Lee KT, Chen HY, Juan CC. Liver surgery for hepatocellular carcinoma: laparoscopic versus open approach. Int J Hepatol 2011;2011:596792.

10. Croome KP, Yamashita MH. Laparoscopic vs open hepatic resection for benign and malignant tumors: an updated meta-analysis. Arch 
Surg 2010;145:1109-18.

11. Yin Z, Fan X, Ye H, Yin D, Wang J. Short- and long-term outcomes after laparoscopic and open hepatectomy for hepatocellular carcinoma: a global systematic review and meta-analysis. Ann Surg Oncol 2013;20:1203-15.

12. Cannon RM, Saggi B, Buell JF. Evaluation of a laparoscopic liver resection in the setting of cirrhosis. HPB (Oxford) 2014;16:164-9.

13. Yoon YI, Kim KH, Kang SH, Kim WJ, Shin MH, Lee SK, Jung DH, Park GC, Ahn CS, Moon DB, Ha TY, Song GW, Hwang S, Lee SG. Pure laparoscopic versus open right hepatectomy for hepatocellular carcinoma in patients with cirrhosis. Ann Surg 2017;265:856-63.

14. Cheung TT, Dai WC, Tsang SHY, Chan AC, Chok KS, Chan SC, Lo CM. Pure laparoscopic hepatectomy versus open hepatectomy for hepatocellular carcinoma in 110 patients with liver cirrhosis: a propensity analysis at a single center. Ann Surg 2016;264:612-20.

15. Zhou YM, Shao WY, Zhao YF, Xu DH, Li B. Meta-analysis of laparoscopic versus open resection for hepatocellular carcinoma. Dig Dis Sci 2011;56:1937-43.

16. Xiong JJ, Altaf K, Javed MA, Huang W, Mukherjee R, Mai G, Sutton R, Liu XB, Hu WM. Meta-analysis of laparoscopic vs open liver resection for hepatocellular carcinoma. World J Gastroenterol 2012;18:6657-68.

17. Han HS, Shehta A, Ahn S, Yoon YS, Cho JY, Choi Y. Laparoscopic versus open liver resection for hepatocellular carcinoma: casematched study with propensity score matching. J Hepatol 2015;63:643-50.

18. Takahara T, Wakabayashi G, Beppu T, Aihara A, Hasegawa K, Gotohda N, Hatano E, Tanahashi Y, Mizuguchi T, Kamiyama T, Ikeda T, Tanaka S, Taniai N1, Baba H, Tanabe M, Kokudo N, Konishi M, Uemoto S, Sugioka A, Hirata K, Taketomi A, Maehara Y, Kubo S, Uchida E, Miyata H, Nakamura M, Kaneko H, Yamaue H, Miyazaki M, Takada T. Long-term and perioperative outcomes of laparoscopic versus open liver resection for hepatocellular carcinoma with propensity score matching: a multi-institutional Japanese study. J Hepatobiliary Pancreat Sci 2015;22:721-7.

19. Cherqui D, Soubrane O. Laparoscopic liver resection: an ongoing revolution. Ann Surg 2017;265:864-5.

20. Xu HW, Liu F, Li HY, Wei YG, Li B. Outcomes following laparoscopic versus open major hepatectomy for hepatocellular carcinoma in patients with cirrhosis: a propensity score-matched analysis. Surg Endosc 2018;32:712-9.

21. Morise Z, Ciria R, Cherqui D, Chen KH, Belli G, Wakabayashi G. Can we expand the indications for laparoscopic liver resection? A systematic review and meta-analysis of laparoscopic liver resection for patients with hepatocellular carcinoma and chronic liver disease. J Hepatobiliary Pancreat Sci 2015;22:342-52.

22. Goumard C, Komatsu S, Brustia R, Fartoux L, Soubrane O, Scatton O. Technical feasibility and safety of laparoscopic right hepatectomy for hepatocellular carcinoma following sequential TACE-PVE: a comparative study. Surg Endosc 2017;31:2340-9.

23. Cheung TT, Han HS, She WH, Chen KH, Chow PKH, Yoong BK, Lee KF, Kubo S, Tang CN, Wakabayashi G. The Asia Pacific consensus statement on laparoscopic liver resection for hepatocellular carcinoma: a report from the 7th Asia-Pacific primary liver cancer expert meeting held in Hong Kong. Liver Cancer 2018;7:28-39.

24. Soubrane O, Goumard C, Laurent A, Tranchart H, Truant S, Gayet B, Salloum C, Luc G, Dokmak S, Piardi T, Cherqui D, Dagher I, Boleslawski E, Vibert E, Sa Cunha A, Belghiti J, Pessaux P, Boelle PY, Scatton O. Laparoscopic resection of hepatocellular carcinoma: a French survey in 351 patients. HPB (Oxford) 2014;16:357-65.

25. Dagher I, Gayet B, Tzanis D, Tranchart H, Fuks D, Soubrane O, Han HS, Kim KH, Cherqui D, O'Rourke N, Troisi RI, Aldrighetti L, Bjorn E, Abu Hilal M, Belli G, Kaneko H, Jarnagin WR, Lin C, Pekolj J, Buell JF, Wakabayashi G. International experience for laparoscopic major liver resection. J Hepatobiliary Pancreat Sci 2014;21:732-6.

26. Halls MC, Cipriani F, Berardi G, Barkhatov L, Lainas P, Alzoubi M, D’Hondt M, Rotellar F, Dagher I, Aldrighetti L, Troisi RI, Edwin B, Hilal MA. Conversion for unfavorable intraoperative events results in significantly worst outcomes during laparoscopic liver resection: lessons learned from a multicenter review of 2861 cases. Ann Surg 2017; doi: 10.1097/SLA.0000000000002332.

27. Belli G, Fantini C, Belli A, Limongelli P. Laparoscopic liver resection for hepatocellular carcinoma in cirrhosis: long-term outcomes. Dig Surg 2011;28:134-40.

28. Kang WH, Kim KH, Jung DH, Park GC, Kim SH, Cho HD, Lee SG. Long-term results of laparoscopic liver resection for the primary treatment of hepatocellular carcinoma: role of the surgeon in anatomical resection. Surg Endosc 2018; doi: 10.1007/s00464-018-6194-0.

29. Guro H, Cho JY, Han HS, Yoon YS, Choi Y, Kim S, Kim K, Hyun IG. Outcomes of major laparoscopic liver resection for hepatocellular carcinoma. Surg Oncol 2018;27:31-5.

30. Han HS, Cho JY, Yoon YS. Techniques for performing laparoscopic liver resection in various hepatic locations. J Hepatobiliary Pancreat Surg 2009;16:427-32.

31. Herman P, Krüger J, Lupinacci R, Coelho F, Perini M. Laparoscopic bisegmentectomy 6 and 7 using a glissonian approach and a halfpringle maneuver. Surg Endosc 2013;27:1840-1.

32. Yoon YS, Han HS, Cho JY, Ahn KS. Total laparoscopic liver resection for hepatocellular carcinoma located in all segments of the liver. Surg Endosc 2010;24:1630-7.

33. Ishizawa T, Gumbs AA, Kokudo N, Gayet B. Laparoscopic segmentectomy of the liver: from segment I to VIII. Ann Surg 2012;256:959-64.

34. Belli G, Cioffi L, Fantini C, D’Agostino A, Russo G, Limongelli P, Belli A. Laparoscopic redo surgery for recurrent hepatocellular carcinoma in cirrhotic patients: feasibility, safety, and results. Surg Endosc 2009;23:1807-11.

35. Laurent A, Tayar C, Andréoletti M, Lauzet JY, Merle JC, Cherqui D. Laparoscopic liver resection facilitates salvage liver transplantation for hepatocellular carcinoma. J Hepatobiliary Pancreat Surg 2009;16:310-4.

36. Lei JY, Wang WT, Yan LN, Wen TF, Li B. Radiofrequency ablation versus surgical resection for small unifocal hepatocellular carcinomas. Medicine (Baltimore) 2014;93:e271.

37. Kang TW, Kim JM, Rhim H, Lee MW, Kim YS, Lim HK, Choi D, Song KD, Kwon CH, Joh JW, Paik SW, Paik YH, Ahn JH. Small 
hepatocellular carcinoma: radiofrequency ablation versus nonanatomic resection--propensity score analyses of long-term outcomes. Radiology 2015;275:908-19.

38. Song J, Wang Y, Ma K, Zheng S, Bie P, Xia F, Li X, Li J, Wang X, Chen J. Laparoscopic hepatectomy versus radiofrequency ablation for minimally invasive treatment of single, small hepatocellular carcinomas. Surg Endosc 2016;30:4249-57.

39. Kim GA, Shim JH, Kim MJ, Kim SY, Won HJ, Shin YM, Kim PN, Kim KH, Lee SG, Lee HC. Radiofrequency ablation as an alternative to hepatic resection for single small hepatocellular carcinomas. Br J Surg 2016;103:126-35.

40. Harada N, Shirabe K, Maeda T, Kayashima H, Takaki S, Maehara Y. Comparison of the outcomes of patients with hepatocellular carcinoma and portal hypertension after liver resection versus radiofrequency ablation. World J Surg 2016;40:1709-19.

41. Cucchetti A, Piscaglia F, Cescon M, Ercolani G, Pinna AD. Systematic review of surgical resection vs radiofrequency ablation for hepatocellular carcinoma. World J Gastroenterol 2013;19:4106-18. 